\title{
Dolasetron for the prevention of postoperative vomiting in children undergoing strabismus surgery
}

\author{
DEBORAH WAGNER Pharm D, UMA PANDIT MD, TERRI \\ VOEPEL-LEWIS RN AND MONICA WEBER RN \\ University of Michigan Health Systems, Department of Pediatric Anesthesia, Ann Arbor, MI, \\ USA
}

\section{Summary}

Background: Children undergoing strabismus surgery have a high incidence of postoperative vomiting (POV). The purpose of this study was to assess the efficacy and safety of dolasetron for the prevention of emesis comparing a single $0.35 \mathrm{mg} \cdot \mathrm{kg}^{-1}$ or $12.5 \mathrm{mg}$ dose with placebo. Methods: Children aged 2-12 years with an ASA status of 1 or 2 undergoing strabismus surgery were randomized in a double-blind manner to one of three treatment groups. Patients were excluded with a history of previous postoperative vomiting or motion sickness, allergy to serotonin receptor antagonists or previous antiemetic administration within $24 \mathrm{~h}$ prior to enrollment.

General anaesthesia was induced with sevoflurane and $\mathrm{N}_{2} \mathrm{O} / \mathrm{O}_{2}$ and maintained with isoflurane and $\mathrm{N}_{2} \mathrm{O} / \mathrm{O}_{2}$. The study medication was administered $15 \mathrm{~min}$ prior to the end of surgery. Patients experiencing two or more episodes of vomiting were rescued in the postanaesthesia care unit (PACU) with metoclopramide $0.15 \mathrm{mg} \cdot \mathrm{kg}^{-1}$. A total of 118 patients were enrolled with documentation of the number and severity of vomiting episodes, time to awakening, PACU length of stay and postoperative agitation.

Results: Patients with an acute complete response (ACR), defined as no emetic episodes and no rescue medication within $24 \mathrm{~h}$ of study drug administration were $62 \%$ (weight dose), $64 \%$ (fixed dose) and $33 \%$ (placebo, $P<0.05$ ).

Conclusions: There was no statistical difference between the $0.35 \mathrm{mg} \cdot \mathrm{kg}^{-1}$ dose and the fixed $12.5 \mathrm{mg}$ dose of dolasetron with both reducing the incidence of $\mathrm{POV}$.

Keywords: dolasetron; pediatrics; postoperative; nausea; vomiting; strabismus 


\section{Introduction}

The incidence of postoperative vomiting (POV) in children varies from 5 to $80 \%$ (1) and is dependent upon patient-related factors, surgical procedure, anaesthetic agents and postoperative management (2). POV is a leading cause of morbidity in paediatric surgical patients and may be associated with wound dehiscence, pulmonary aspiration, bleeding, dehydration and electrolyte disturbance (3). Furthermore, POV may result in unanticipated hospital admission, prolonged length of stay, increased health care costs and decreased patient satisfaction.

Postoperative vomiting is mediated by a variety of receptors including dopaminergic, muscarinic, serotonergic, histamine and opioid receptors but no single pharmacological agent is currently available to antagonize all of the receptors involved in the emetic reflex response. The serotonin receptor antagonists [5hydroxytryptamine $\left(5-\mathrm{HT}_{3}\right)$ ] were first introduced to prevent chemotherapy induced nausea and vomiting and were found to be highly effective and welltolerated (4). Their antiemetic effects may be the result of the activity at both peripheral neural and central nervous system sites by blocking the effects of serotonin in the chemoreceptor trigger zone (CTZ), nucleus tractus solitarius, and vagal afferents (5). Prophylactic administration of ondansetron and granisetron $5-\mathrm{HT}_{3}$ receptor antagonists have been shown to reduce the incidence of postoperative nausea and vomiting (PONV) in children undergoing strabismus surgery $(6,7)$. A recent study by Sukhani demonstrated comparative efficacy between ondansetron and dolasetron in combination with dexamethasone for POV prophylaxis in children undergoing ambulatory tonsillectomy (8). Pharmacokinetics have been studied in paediatrics (9), however dose finding data in this population are still needed. The purpose of this randomized, double-blind, placebo-controlled trial was to compare the safety and efficacy of intravenous (i.v.) dolasetron in doses of $0.35 \mathrm{mg} \cdot \mathrm{kg}^{-1}$ (maximum dose $12.5 \mathrm{mg}$ ) or a single fixed dose of $12.5 \mathrm{mg}$, compared with placebo for the prevention of POV following strabismus repair in children.

\section{Methodology}

Following approval from the Institutional Review Board and written informed consent from a parent or legal guardian, children aged 2-12 years of age, with an ASA classification of 1-2, scheduled for outpatient strabismus surgery were enrolled. Children with the following conditions were excluded: allergy to $5-\mathrm{HT}_{3}$ agents, previous $\mathrm{POV}$, motion sickness, hepatic, renal, cardiac or neurological disorders, and use of an antiemetic within $24 \mathrm{~h}$ of surgery. Children were randomly assigned to one of the three study groups using a $2: 2: 1$ randomization schedule. The dose per weight group received $0.35 \mathrm{mg} \cdot \mathrm{kg}^{-1}$ dolasetron, the standard dose group a fixed dose of $12.5 \mathrm{mg}$ of dolasetron, and the third group received placebo of sodium chloride $0.9 \%$. All study drug was provided in an identical volume for all three arms of the study. The pharmacist at the site was responsible for the blinding and preparation of the drug.

Preoperatively, all children received acetaminophen $\left(15 \mathrm{mg} \cdot \mathrm{kg}^{-1}\right)$ orally $30 \mathrm{~min}$ prior to induction, and midazolam was administered at the discretion of the attending anaesthesiologist. General anaesthesia was induced with sevoflurane and nitrous oxide $(60 \%)$ in oxygen via facemask. A laryngeal mask airway $\left(\mathrm{LMA}^{\mathrm{TM}}\right)$ was placed and anaesthesia was maintained with isoflurane in nitrous oxide/ oxygen. An i.v. line was started, and i.v. fluids were administered as per preexisting guidelines to replace preoperative deficits and provide standard maintenance fluids. Prior to surgical incision, ketorolac $0.5 \mathrm{mg} \cdot \mathrm{kg}^{-1}$ i.v. was administered. Atropine $20 \mu \mathrm{g} \cdot \mathrm{kg}^{-1}$ i.v. was administered as needed to treat oculocardiac reflex. Fifteen minutes prior to the end of the procedure, the study drug was administered. At the completion of surgery, the patient was turned to one side, the LMA was removed with the cuff inflated and the oropharynx suctioned.

Postoperatively, children were monitored for any episode of POV or retching. The severity of POV was classified as mild (one episode), moderate (two episodes), or severe (three or more episodes). Two or more episodes of vomiting or retching were treated with metoclopramide $0.15 \mathrm{mg} \cdot \mathrm{kg}^{-1}$ i.v. (maximum $10 \mathrm{mg}$ ). The primary efficacy measure was an acute complete response (ACR) which was defined as no POV or rescue antiemetic medication use within $24 \mathrm{~h}$. Postoperative pain was assessed using the Faces, Legs, Activity Cry and Consolability (FLACC) observational pain scale (10), and children with scores of $\geq 4$ were treated with morphine sulphate 
$0.05-0.1 \mathrm{mg} \cdot \mathrm{kg}^{-1}$ i.v. at the discretion of the postanaesthesia care unit (PACU) nurse.

The time to awakening and the length of stay in the PACU were recorded. Adverse events including postoperative agitation were documented. The parents were telephoned the following day to obtain the following information: the occurrence and severity of POV on the trip home and within $24 \mathrm{~h}$, medications administered, adverse events, and parental satisfaction with the prevention and treatment of POV using a $1-4$ scale $(1=$ very dissatisfied, $2=$ dissatisfied, $3=$ satisfied, $4=$ very very satisfied).

\section{Statistical methods}

Categorical data such as ACR, and the incidence and severity of POV were compared using chi-square with Fisher's exact tests as appropriate. Parametric data such as patient age, and weight were compared using unpaired $t$-tests. Data are reported as mean $\pm \mathrm{SD}$ or $n(\%)$ as appropriate. $P$ values of $\leq 0.05$ were considered statistically significant. A power analysis performed prior to this investigation demonstrated that 20 patients per group would be sufficient to detect a reduction of $60 \%$ in the incidence of POV in $24 \mathrm{~h}$ assuming an incidence of $70 \%$ in the placebo group $(\alpha=0.05 ; \beta=0.20)$. In order to reduce exposure to placebo, while providing sufficient number of subjects to allow evaluation of the safety and efficacy of each dosing group, a $2: 2: 1$ assignment to treatment and control groups, respectively, was used.

\section{Results}

A total of 118 children were enrolled and included in the intent-to-treat population (46, 48 and 24 in the dose per weight group, fixed dose and placebo groups, respectively). Nineteen children required tracheal intubation instead of an LMA, and three received halothane in place of sevoflurane. POV data were missing for two children as they were lost to follow-up. Data from each of these children were therefore excluded from analysis, which resulted in a total of 94 children enrolled. Demographic and perioperative data were similar between the three study groups (Table 1).

Data regarding POV, rescue medications and other outcome measures are presented in Table 2 . The ACR was significantly lower for children who received placebo compared with those who received dolasetron in either the fixed dose or dose per weight. There was no difference in ACR between the two active treatment groups. Furthermore, the ACR was significantly lower in patients who received morphine $(46 \%)$ compared with those who did not $(66 \% ; P=0.05)$. The median times to first emetic episode were $195 \pm 63 \mathrm{~min}, 255 \pm 105 \mathrm{~min}$ and $188 \pm 41 \mathrm{~min}$ for $0.35 \mathrm{mg} \cdot \mathrm{kg}^{-1}, 12.5 \mathrm{mg}$ dolasetron and placebo groups, respectively. Children who vomited in the hospital had a significantly longer PACU stay compared with those who did not vomit $(141 \pm 59$ vs $105 \pm 26$ min respectively; $P<0.001)$. In all groups $94-97 \%$ of parents were satisfied to very satisfied with the care and no children were admitted to the hospital as a result of

\begin{tabular}{|c|c|c|c|}
\hline & $\begin{array}{l}\text { Dose per weight } \\
\quad(\mathrm{n}=36)\end{array}$ & $\begin{array}{l}\text { Standard dose } \\
\quad(\mathrm{n}=40)\end{array}$ & $\begin{array}{l}\text { Placebo } \\
(\mathrm{n}=18)\end{array}$ \\
\hline Age & $4.8 \pm 3$ & $5.3 \pm 3$ & $5.4 \pm 3$ \\
\hline Weight (kg) & $20.4 \pm 8.9$ & $22.6 \pm 10.3$ & $22.1 \pm 9.5$ \\
\hline Male gender & $18(49 \%)$ & $19(48 \%)$ & $7(39 \%)$ \\
\hline \multicolumn{4}{|l|}{ ASA status } \\
\hline ASA 1 & $28(78 \%)$ & $33(83 \%)$ & $14(78 \%)$ \\
\hline ASA 2 & $7(19 \%)$ & $7(18 \%)$ & $4(22 \%)$ \\
\hline Midazolam $(n / \%)\left(\mathrm{mg} \cdot \mathrm{kg}^{-1}\right)$ & $3 / 8(0.5 \pm 0.08)$ & $2 / 5(0.3 \pm 0.15)$ & $2 / 11(0.5 \pm 0.03)$ \\
\hline Morphine $(n / \%)\left(\mathrm{mg} \cdot \mathrm{kg}^{-1}\right)$ & $17 / 44(0.06 \pm 0.03)$ & $15 / 38(0.06 \pm 0.2)$ & $7 / 39(0.05 \pm 0.02)$ \\
\hline Atropine $(n / \%)$ & $2 / 6$ & $3 / 8$ & 0 \\
\hline Anaesthesia duration (min) & $63 \pm 19$ & $60 \pm 16$ & $61 \pm 13$ \\
\hline Dolasetron dose $\left(\mathrm{mg} \cdot \mathrm{kg}^{-1}\right)$ & $0.35 \pm 0.01$ & $0.67 \pm 0.28^{*}$ & NA \\
\hline
\end{tabular}

Table 1

Demographic and perioperative data of the study groups

${ }^{*} P<0.001$ compared with dose per weight group. 
Table 2

Postoperative outcomes between the study groups

\begin{tabular}{|c|c|c|c|}
\hline & $\begin{array}{l}\text { Dose per weight } \\
\quad(\mathrm{n}=36)\end{array}$ & $\begin{array}{l}\text { Standard dose } \\
\quad(\mathrm{n}=40)\end{array}$ & $\begin{array}{l}\text { Placebo } \\
(\mathrm{n}=18)\end{array}$ \\
\hline POV in hospital & $6(17 \%)$ & $8(21 \%)$ & $9(50 \%)^{*}$ \\
\hline POV at home & $14(38 \%)$ & $13(33 \%)$ & $9(50 \%)$ \\
\hline Rescue antiemetic administered & $2(6 \%)$ & $3(8 \%)$ & $5(28 \%)^{* *}$ \\
\hline \multicolumn{4}{|l|}{ Vomiting severity } \\
\hline Mild (one episode) & $4(11 \%)$ & $5(13 \%)$ & $3(17 \%)$ \\
\hline Moderate (two episodes) & $3(8 \%)$ & $2(5 \%)$ & $2(11 \%)$ \\
\hline Severe ( $\geq 3$ episodes) & $7(19 \%)$ & $7(18 \%)$ & $7(39 \%)$ \\
\hline ACR & $23(62 \%)$ & $25(64 \%)$ & $6(33 \%)^{*}$ \\
\hline Relative risk $(\mathrm{CI})^{\mathrm{a}}$ & $0.57(0.34-0.96)$ & $0.53(0.32-0.92)$ & \\
\hline \multicolumn{4}{|l|}{ Adverse effects } \\
\hline Headache & $6(18 \%)$ & $10(27 \%)$ & $6(33 \%)$ \\
\hline Abdominal pain & $4(12 \%)$ & $2(5 \%)$ & $3(17 \%)$ \\
\hline Constipation & $3(8 \%)$ & 0 & 0 \\
\hline PACU length of stay (min) & $113 \pm 42$ & $108 \pm 39$ & $124 \pm 31$ \\
\hline
\end{tabular}

${ }^{*} P \leq 0.044$ compared with either treatment group.

${ }^{*} P=0.032$ compared with weight dose.

${ }^{a}$ Relative risk reduction of postoperative vomiting (POV) in $24 \mathrm{~h}$ compared with placebo. CI, confidence interval; $\mathrm{ACR}$, acute complete response; PACU, postanaesthesia care unit.
POV. More parents of children with moderate to severe vomiting were dissatisfied with their child's care $(12 \%)$ compared with those whose children had none or mild vomiting across all groups $(0 \%$; $P=0.02)$.

\section{Discussion}

This study demonstrates that prophylactic administration of i.v. dolasetron in a fixed dose of $12.5 \mathrm{mg}$ or in a per weight dose of $0.35 \mathrm{mg} \cdot \mathrm{kg}^{-1}$ reduces the incidence and severity of POV in children undergoing strabismus surgery compared with placebo while in the hospital. There were no differences in the incidence or severity of POV nor in adverse events between the two dolasetron doses. However, this study may have been underpowered to detect such differences.

Dolasetron has been shown to be safe and effective in treating PONV in adults at doses of $12.5 \mathrm{mg}$ (11). Previous pharmacokinetic data have demonstrated that the clearance of dolasetron is greater in children compared with adults, possibly because of increased drug metabolism (9). Therefore, higher doses of dolasetron may be required to prevent or reduce nausea and vomiting in children. A recent study demonstrated that $0.6-2.4 \mathrm{mg} \cdot \mathrm{kg}^{-1}$ of dolasetron reduced chemotherapy-induced nausea and vomiting in children aged 2-17 years, however, there were insufficient data to determine statistical differences (12). Yet, the current dolasetron package insert recommends a dose of $0.35 \mathrm{mg} \cdot \mathrm{kg}^{-1}$ (maximum $12.5 \mathrm{mg}$ ) for patients aged 2-16 years. Our data suggest that dolasetron administered i.v. in a fixed dose of $12.5 \mathrm{mg}$ or as a per weight dose of $0.35 \mathrm{mg} \cdot \mathrm{kg}^{-1}$ effectively reduces POV in children undergoing strabismus surgery. Additionally the long half-life of the active metabolite hydrodolasetron may provide prolonged benefit for delayed emesis $(9,13)$.

This study demonstrated no advantage nor disadvantage between the fixed or per weight doses in terms of efficacy or side-effects. Headache was the most frequently reported adverse event across all groups, and was not significantly different for either dosing group compared with placebo, and was similar to its reported incidence in previous studies (12). Seventeen children in the $12.5 \mathrm{mg}$ fixed dose group received doses of $\geq 0.7 \mathrm{mg} \cdot \mathrm{kg}^{-1}$, twice the weight based dose, to a maximum of $1.25 \mathrm{mg} \cdot \mathrm{kg}^{-1}$ (one patient) with no difference in the occurrence of adverse events. Our sample of these children, however, may have been too small to detect such differences. Administration of a fixed dose of dolasetron has the advantages of efficient administration and reduced calculation errors, whereas a 
weight-based dose may offer a small cost advantage through use of the multidose vial preparation. Other $5-\mathrm{HT}_{3}$ inhibitors, such as ondansetron, have been shown to reduce POV in paediatric strabismus surgery (14). Dolasetron offers a safe and effective alternative to ondansetron, at approximately half the acquisition cost. The nature and incidence of sideeffects are similar for each of the $5-\mathrm{HT}_{3}$ inhibitor antiemetics with mild ECG changes being reported (11). These changes however have not been seen in dolasetron doses of $12.5 \mathrm{mg}$ in paediatric patients for the prevention of PONV, nor were noted in any of the study patients enrolled (15).

Several factors likely contributed to POV equally across our study groups. All children in our sample received nitrous oxide as a cost-efficient anaesthetic agent, which has been shown to contribute to POV (16). Furthermore, the use of opioid analgesics was found to significantly increase the incidence of POV in our sample. Using alternative methods of anaesthesia and analgesia may further reduce $\mathrm{POV}$ in children undergoing high-risk emetogenic surgery. In this study the results were not effected by the choice of anaesthetic technique as all patients received a standardized technique. Furthermore, POV prevention may be enhanced by combining antiemetics that act on different receptor sites (11).

Prophylactic administration of antiemetics has been recommended for patients at high risk for POV, such as children undergoing strabismus surgery (11). The choice of antiemetic for prevention of POV should be based on the patient's risk factors, the cost of the drug and the potential for adverse effects. The 5- $\mathrm{HT}_{3}$ antagonists offer a welltolerated and effective group of agents for the prevention and treatment of POV in children. Dolasetron may represent the most cost-effective agent in this class of drugs. This study demonstrated that dolasetron administered intravenously in a fixed dose of $12.5 \mathrm{mg}$ or in a $0.35 \mathrm{mg} \cdot \mathrm{kg}^{-1}$ (maximum of $12.5 \mathrm{mg}$ ) dose at the end of surgery reduced the incidence and severity of POV in children undergoing strabismus surgery. Further study in a larger sample may be necessary to determine the risk benefit ratio for the fixed vs per weight dose.

\section{Acknowledgement}

This research was supported by a grant from Aventis Pharmaceuticals.

\section{References}

1 Baines D. Postoperative nausea and vomiting in children. Paediatr Anaesth 1996; 6: 7-14.

2 Sung Y. Risks and benefits of drugs used in the management of PONV. Drug Safety 1996; 14: 181-197.

3 Rose JB, Watcha MF. Postoperative nausea and vomiting in paediatric patients. BJA 1999; 83: 104-117.

4 Hesketh PJ. Comparative review of $5 \mathrm{HT}_{3}$ receptor antagonists in the treatment of acute chemotherapy induced nausea and vomiting. Cancer Invest 2000; 18: 163-173.

5 Wadibia EC. Antiemetics. Southern Med J 1999; 92: 162-166.

6 Bowhay AR, May HA, Rudnicka AR et al. A randomized controlled trial of the antiemetic effect of three dose of ondansetron after strabismus surgery in children. Paediatr Anaesth 2001; 11: 215-221.

7 Munro H, D'Errico CC, Tait AR et al. Dose response of oral granisetron in paediatric strabismus surgery. Can J Anesth 1999; 46: 45-48.

8 Sukhani R, Pappas AL, Lurie J et al. Ondansetron and dolasetron provide equivalent postoperative vomiting control after ambulatory tonsillectomy in dexamethasone-pretreated childen. Anesth Analg 2002; 95: 1230-1235.

9 Lerman J, Sims C, Sikich N et al. Pharmacokinetics of the active metabolite (MDL 74, 156) of dolasetron mesylate after oral or intravenous administration to anesthetized children. Clin Pharmacol Ther 1996; 60: 485-492.

10 Merkel S, Malviya S. Pediatric pain, tool and assessment. J Perianesthesia Nurs 2000; 15: 408-414.

11 Kovac AL. Prevention and treatment of postoperative nausea and vomiting. Drugs 2000; 59: 213-243.

12 Whitmore JB, Kris MG, Hesketh PJ et al. Rationale for the use of a single fixed intravenous dolasetron dose for the prevention of cisplatin-induced nausea and vomiting. Pooled analysis of 14 clinical trials. Support Care Cancer 1998; 6: 473-478.

13 Shah A, Lanman R, Bhargava V et al. Pharmacokinetics of dolasetron following single and multiple-dose administration to normal male subjects. Biopharm Drug Dispos 1995; 16: 177189.

14 Tramer MR. A rationale approach to the control of postoperative nausea and vomiting: evidence from systematic reviews. Acta Anaesthesiol Scand 2001; 45: 4-13.

15 Howard D, Chin C, Meyerson J. Open-label pharmacokinetic and safety evaluation of a single IV dose $(1.2 \mathrm{mg} / \mathrm{kg})$ of MDL 73, 147EK (dolasetron mesylate) in children undergoing elective and uncomplicated surgery under general anesthesia. Protocol ANPD-0593. Marion Merrell Dow (MMD) Report K-950121-CD 1995.

16 Pandit UA, Malviya S, Lewis IH. Vomiting after outpatient tonsillectomy and adenoidectomy in children: the role of nitrous oxide. Anesth Analg 1995; 80: 230-233.

Accepted 31 January 2003 